\title{
Conflict Resolution Skills For New Staff Accountants And Auditors
}

\author{
Dean DiGregorio, Southeastern Louisiana University
}

\begin{abstract}
This case is designed to help accounting students learn and apply conflict resolution skills that they will need to be successful in the workplace. Accounting students need to develop strong technical and people skills in order to become successful accountants or auditors. This is true whether they enter public accounting, industry or government. Technical skills enable a professional to do the work required in an efficient, timely and accurate manner. They are learned in school, on the job, and through specialized training. People skills enable a professional to work successfully with those inside and outside of the organization. Unlike technical skills, a professional might never receive any formal training regarding people skills. This is unfortunate as people that do not get along with others and resolve conflicts in a productive manner are highly unlikely to attain long-term success. People skills include being able to: establish rapport and get along with others; comfortably work with people with diverse backgrounds and personality types; successfully resolve interpersonal conflicts; influence, persuade and negotiate with others; and to effectively train, supervise, and lead others. Most of the skills are interrelated and a weakness in any of the above areas can either create conflict, or hinder a person's ability to resolve it. When two or more people interact, the possibility of conflict exists. Conflict in the workplace often arises from diversity issues, from people that seem to be in constant conflict with those around them, and when people bring their personal problems to work. Conflict is also likely when company policies are perceived as unfair or arbitrary, when people have control issues and micro-manage others, when reviewers or reviewees act unprofessional, and when there is intense competition for personal rewards or organizational resources. Successful conflict resolution can be complicated. Some situations can not be changed and should either be avoided in the first place, ignored (coped with), or escaped from. Other situations can be resolved through persuasion, influence, and negotiation. Further, the methods used to resolve conflicts may differ based on whether the professional is dealing with a client, a peer, or someone with more or less power than they have.
\end{abstract}

Keywords: Conflict resolution in workplace, Diversity, Persuasion, Influence, Negotiation, Workplace conflict

\section{INTRODUCTION}

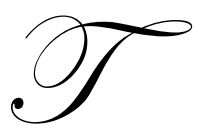

his case is designed to help accounting students learn and apply conflict resolution skills that they will need to be successful in the workplace. Secondary issues examined include embracing workplace diversity, and successfully using persuasion, influence and negotiation skills. The case is appropriate for sophomore-level students in managerial accounting classes. It is also relevant and appropriate for senior-level students taking auditing or other upper-level accounting classes. The case is designed to be taught in a 1.25 hour class and is expected to require 2.5 hours of outside preparation by students, preferably working in small groups. Alternatively, the case could be assigned as a project that requires minimal classroom time.

The suggested student questions are designed to help students analyze the situation and apply the appropriate strategies and techniques for dealing with conflicts in the workplace. Students can be provided with the opportunity to improve their analytical and written communication skills by requiring that answers be turned in 
before class discussion. Discussing the case in class offers students the opportunity to improve their verbal communication skills and exposes them to alternative ways of handling each situation.

John and Susan are two friends that graduated with their accounting degrees and went to work in industry and public accounting, respectively. While talking they got on the subject of people skills and dealing with the various situations that arose at work. They agreed that while the technical work was challenging, they felt confident that they could do it successfully due to their accounting education and the on-the-job training they received.

In contrast, they noticed that most of the problems they observed and experienced were people related. Neither had any classes or formal training related to dealing with the inevitable conflicts that arose at work. Both felt frustrated at times and noticed that others had done damage to their careers by mishandling people problems at work. They also observed that some people were very good at dealing with others and moved up the corporate ladder quickly.

With further conversation they realized that many of the conflicts could fit into certain categories. In particular they noted that the conflicts arose from diversity issues, from people that seemed to be in constant conflict with those around them, and when people brought their personal problems to work. Conflict was also likely when company policies were perceived as unfair or arbitrary, when people had control issues and micro-managed others, when reviewers or reviewees acted unprofessional, and when there was intense competition for personal rewards or organizational resources.

At first John and Susan felt a little overwhelmed when trying to figure out how to successfully handle the different types of conflicts they observed. However, they decided to divide up the problems, observe people at work that seemed to handle the problems successfully, and do some reading. They agreed to meet again in a few weeks to share their notes and observations.

At their next meeting, John and Susan compared notes and identified several alternative strategies (Cloke \& Goldsmith, 2005; Bramson, 1992) that could be used to productively deal with conflict. The options they came up with are listed below.

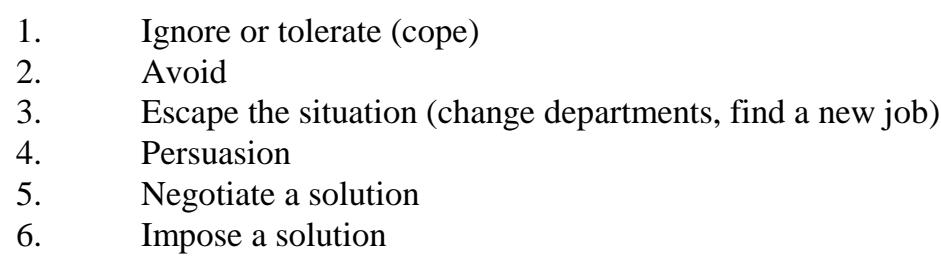

John and Susan also identified strategies designed to harass, undermine, and destroy an opponent (Dubrin, 1978). However, they also observed that while those strategies could be successful in the short-term, they carried a high personal cost and could easily backfire and cause more problems than they were worth in the workplace. They both decided that they would not resort to personal attacks, harassment, malicious gossip, blaming others, backstabbing, withholding information or resources, faking agreement, sabotaging, and other forms of outright or guerilla warfare.

\section{Ignore, Avoid, Escape}

John and Susan agreed that many things were not worth fighting over or getting upset about. Frequently the issues were immaterial or merely related to differences in personal preferences. Similar to being in a relationship, they had to let some things slide and pick their battles wisely. They also observed that problems could often be prevented and irritating people avoided with a little forethought. 
However, in some cases the issues were important enough to deal with. In cases where John and Susan had no control or ability to negotiate, they realized that their only choices were to tolerate or escape the situation. They agreed that feeling helpless or agonizing over things that could not be changed would be a waste of their time and effort. They also felt that some situations could be ridden out and would eventually change because they could not exist for long the way they were. John and Susan also agreed that a problem had to seriously threaten their career or personal happiness before they would make a lateral job change. They didn't want to be known as people that quit and ran at the first sign of trouble or that changed jobs every 6 months.

\section{Persuasion}

Fortunately, many problem situations do lend themselves to persuasion or a negotiated solution, even when the people involved have different levels of power. Persuasion can be used to help people recognize that they can get what they want, or avoid what they don't want, by voluntarily making certain choices. Susan took a personal selling class while in school because she knew that to make partner and have any real power, she needed to bring business into the firm. In class she learned to establish rapport, ask questions to uncover motives, structure a presentation, handle objections, and ask for the order (Whiting, 1978). She realized that the sales skills she learned in school would also be useful when trying to persuade and influence people at work.

Susan explained to John that most sales calls began with the salesperson trying to establish rapport with the prospect. A friendly, positive attitude combined with an interest in the other person usually made the other person much more open to listening to the salesperson's message than they otherwise would have been. A basic principle of persuasion is that people do things for people they like, and things to people they don't like. Dale Carnegie (1981) stressed that a smile, sincere compliment, and follow-up question could open may doors. He also noted that a person can make a lot more friends by being interested in others, rather than trying to make others interested in them. She also read that practitioners of neuro-linguistic programming (NLP) suggest that people should match and mirror, without mimicking, the people they are trying to establish rapport with (Hogan 1996). For example, people should use similar body language (i.e. posture, facial expressions, mannerisms) and vocal characteristics (i.e. volume, speed, pitch, buzz words) as the people they want to establish rapport with. Matching and mirroring works because a high percentage of communication is nonverbal and people usually feel most comfortable with people that are "just like them."

Susan also explained that salespeople ask questions to uncover prospect's wants and fears. Most people move towards pleasure or gain, and away from pain or loss. Also, most people buy based on emotion and justify their choices with logic. So, salespeople usually use a carrot and the stick approach when making presentations. They stress the benefits to be obtained by taking action, the costs of not taking action, and back up each claim with proof (Whiting, 1978).

When specific objections to the sale can be anticipated, they are raised and answered by salespeople during the presentation. This method nips problems in the bud. In addition, many people automatically say no to new ideas or change. When prospects raise objections to the sale, salespeople can respond in several different ways. Some objections are not real, so the salespeople just ignore them, unless they are repeated more than once. Sometimes prospects just need to vent, so the salespeople just let them blow off steam and then get back to the presentation. In many cases, once prospects hear themselves speak, they realize that the concerns were minor or irrelevant.

If objections are repeated, they usually need to be addressed. Again, salespeople will ask questions to clarify the issue and then test it. That is, they will ask something like "If we can handle that (solve that problem), would you be willing to go ahead with the proposal." If the prospects say yes, the salespeople respond to the objections. If the prospects say no, the salespeople ask what other reasons are holding them back. Once salespeople feel they have identified all of the roadblocks, they usually address them one at a time and gain agreement that the issue has been resolved before moving on to the next objection. 
Objections can be eliminated or overcome in several ways. Misunderstandings can be explained and clarified. Reasons not to proceed can be turned around and used as the reasons to proceed. Legitimate problems can be outweighed by the benefits of taking action and minimized by putting the issue in perspective (for example, cost per day).

Finally, salespeople ask for action (the order). They can assume the prospects will buy and congratulate them on making the decision to proceed. If the prospects don't resist, they have agreed to the offer. Prospects can also be offered alternatives such as "would they like to proceed with option A or would they prefer to go with option B." To get an immediate agreement to action, salespeople may try to create fear of loss by noting that "the sale ends tomorrow", or that "the item is the last one in stock." If prospects still hesitate to commit, salespeople can take the risk out of the decision by asking the prospects to "just give it a try" and telling the prospect "if it doesn't do what I said it would do, you can just return the product (or cancel the service)."After thinking about what Susan had said about the sales process, John agreed that it could easily be adapted to dealing with conflicts at work.

John also realized that the sales process incorporated the principles of persuasion and influence that he had read about (Cialdini, 1993). He agreed with Susan that people are more easily influenced when they like the other person and the appeal is to their own self-interests. He also pointed out that most people can be led and tend to listen to authority. They also want to belong or fit in and look for social proof. That is, before making decisions, they consciously or unconsciously consider what everyone else is doing. They tend to want what others want and do what others do. People also often want what they can't have and scarcity tends to increase perceived value. Also, most people feel a strong sense of reciprocation. If they are given something, they tend to feel some obligation to return the favor. In addition, people feel the need to be consistent with their self image and prior actions. Once they start something, it is hard to stop.

\section{Negotiation}

John also observed negotiations on a regular basis at his company. He realized that negotiation could be considered a form of persuasion, but it usually involved more give and take by both sides. He noted that negotiation styles could differ depending on whether the transaction was a one time thing, or whether the parties expected to deal with each other on a regular basis. If the parties never expected to deal with each other again, or one side had much more power than the other, the temptation was for each side to try to win big at the expense of the other side. Unfortunately, the win-lose approach often resulted in no deal or a deal that was later reneged on or sabotaged by the loser (Schatzki \& Coffey, 1981; Fisher, Ury \& Patton, 1991).

John told Susan that when people expect to deal with each other on a regular basis, a win-win approach tends to be more sustainable. Effective negotiators first identify their interests (what they want to accomplish). They do their homework and estimate a range regarding the most they could reasonably expect to get, what they are willing to settle for, and at what point they should walk away with no deal. They also try to estimate a best, worst, and most likely scenario for what they will need to give, in order to get what they want. Each side then asks questions to identify, probe and test the other party's real interests. Negotiators attempt to reach agreement by making offers and counter-offers. If they give enough, they can usually get what they want. However, both sides must be disciplined and be careful not to overpay or give too much to get what they want (Schatzki \& Coffey, 1981; Fisher, Ury \& Patton, 1991).

John also noted that when one person has much more power than another, they may be in position to impose their will on the other person. However, as with negotiations where one side wins big and the other side loses, the loser may retaliate. The loser may respond by reneging on the agreement, sabotaging it, or waging a guerilla warfare campaign to get even. The winner may find they have earned a pyrrhic victory. 


\section{Application}

After their discussion, John and Susan felt much more confident about how to handle the conflicts that regularly arose at work. By identifying the basic strategies of ignore, tolerate (cope), avoid, persuade, negotiate, and impose a solution, they felt that they had developed a useful framework for action. By considering the techniques used in persuasion, personal selling and negotiation, they felt they had identified tools to effectively implement the strategies.

John and Susan next considered the specific instances where conflicts regularly arose at work that they had previously identified. Each shared their experiences and insights to handle conflicts arising from diversity issues, from people that seemed to be in constant conflict with those around them, and from people that brought their personal problems to work. They also discussed what to do when company policies were perceived as unfair or arbitrary, when people had control issues and micro-managed others, when reviewers or reviewees acted unprofessional, and when there was intense competition for personal rewards or organizational resources.

\section{Diversity Issues}

John works as a staff accountant in a large corporation that formally embraces diversity in its mission statement. However, John observed various cliques throughout the organization based on position, departments, interests and demographic factors such as age, gender, race, and religion. He realized that some people moved easily between the groups while others were more comfortable interacting with people that were "just like them." He also noted that many feared change and the unknown.

Through his reading and observation John realized that the people that accepted others the way they were had a lot fewer problems than those with judgmental attitudes. People seemed to sense when they were being judged by others and didn't like it. This made sense as no one likes to be judged as inferior to someone else. He also read that when people assume that everyone has the same values, interests, and goals as they do, then misunderstandings are likely to occur. He realized that he had seen this when innocent comments by one person were interpreted to be insulting by another person. He also saw conflicts between those that put work before family and those that put family before work. On a similar note, he viewed major differences between professionals that had a career and people that just had a job.

\section{Difficult People}

John also observed that there were some people in the corporation that seemed to enjoy drama and created conflict on a regular basis. They were often labeled as difficult or problem people by those that came in contact with them. After doing some reading, he again noted that many of the problem people could be categorized by the way they created conflicts.

Some people constantly criticized and were judgmental toward other people and/or the company. He realized that these were often the same people that had issues with diversity and believed that everyone should have the same values, interests, and goals that they did. On the flip side, John also observed people that were overly sensitive and constantly felt offended. They acted as though every comment or change was directed at them. Others people were very negative, complained about everything, and spread doom and gloom. When these people walked into a room, everyone else headed for the door.

In some cases the conflicts were more than just annoying. Bullies tried to use actual or implied threats to get what they wanted. While slackers, didn't carry their own weight and either tried to trap others into doing their work or played hot potato. That is, make their problems someone else's problems. They were the typical free-riders and helpless people that anyone that ever had to do a group project ran into sooner or later. 
At first John was looking for ways to change the difficult people. However, as he read more and thought about his personal experiences he realized that people do not change unless they want to. Some books focused on recognizing difficult people during the interview process and not hiring them in the first place. Other authors suggested firing the problem people or if that wasn't possible, then isolating them to contain the damage. As John didn't have the power to hire or fire, he had to keep looking for answers.

John soon realized that at his level the only things he could truly control were his own actions and reactions. Rather than get upset, he might as well accept that conflicts were a normal part of life and the better he learned to deal with them, the happier his life would be. He figured that the simplest strategy available to deal with difficult people was to simply avoid them. If that wasn't possible he could ignore them or change the subject (Oxman,1997). John also understood that ignoring people was sometimes easier said than done. Especially, when they were your boss or when they tried to push your emotional buttons. In extreme cases it might be necessary to escape no-win situations by transferring within the company or getting a new job.

John also knew that sometimes it was necessary to deal with difficult people and that he would need to use persuasion and negotiation skills to do it successfully. He realized that it was important to keep his emotions under control, avoid making assumptions about the intentions of the other person, consider the truth of the message, ask questions, and focus on solutions instead of placing blame (Bell \& Smith, 1991; Harris, 2003; Pachter \& Magee, 2000). The advice "be easy on the person and hard on the problem" was repeated often in his readings. John also read that not all questions needed to be answered and recognized that this advice could help him avoid being drawn into unnecessary drama. Also, when necessary he could turn the tables and hand the problem back to the other person by asking questions such as "Why are you asking me that question?", "Why do you say that?" and "What do you think we should do about it?."

John also learned early in his career that there was a difference between taking on more responsibility to grow and become more valuable to the company, versus picking up the work of a slacker. He learned the hard way that it was better to just say "No" and stick to it when asked to do things he didn't want to do, by someone that had no real power over him.

John also knew from childhood how to deal with bullies. He had learned early not to show intimidation or fear. As an adult in the workplace, he realized that other than being fired, there was little someone could actually do to him. Mental intimidation only worked if he bought into it (Bramson, 1992; Brinkman \& Kirschner, 2002). John was not afraid of being fired. He made it a point to meet others in the organization and constantly improved his skills to remain marketable. He had also saved enough to live on for several months and put it in a bank account that he vowed not to touch, except for true emergencies. He knew that his skills and savings were the source of real security. John also knew that most companies have a zero-tolerance level for workplace violence and that if anyone ever physically harassed him, they would be quickly fired.

\section{People Bringing Personal Problems To Work}

Both John and Susan agreed that workplace conflicts were likely when people brought personal problems to work. People with mental health, drug or alcohol problems usually also had performance and people problems. Likewise, if people had family issues and were unhappy at home, it often affected their attitude, disposition, and the way they treated others at work. This created even more problems as people often act like mirrors and reflect back what they see in others. For example, if someone is perceived as unfriendly or negative, they will often be treated in an unfriendly or negative manner by others.

John and Susan agreed that at their level there was little they could do about people bringing personal problems to work. However, they did expect management to do their job and deal with it. Management could recommend or insist on counseling, or if necessary fire the offenders. Depending on the situation, John and Susan would probably choose to avoid it. If they had to deal with the person, they would not take the conflicts personally 
and when possible would be compassionate and recommend counseling. However, they would not get sucked into problems that they were not equipped to deal with or do the other person's work for them.

\section{Corporate Culture And Organizational Structure}

Susan works as an auditor for a mid-sized public accounting firm in a large city. She was recruited while in college and had several interviews and offers from different firms. While interviewing she realized that different firms had different personalities. Some firms were very stiff and formal, some were "work hard and play hard," while others were more family oriented. She realized that she fit in and was much more comfortable at some firms as compared to others. She wisely chose a firm where she felt comfortable and that offered the opportunities she was interested in. Unfortunately, some of her friends went strictly for the money. Some were lucky but others wound up in places that had the wrong environment for them. They didn't fit in, had no mentor, and were soon out of the loop. In a professional service firm, this can be fatal. Susan realized that when someone goes with a firm that has a corporate culture that does not match their personality, they may be better off leaving and going where they will fit in and can become successful. Auditors spend too many hours at work to be with people they don't like or can't get along with.

Susan enjoys the fast pace and challenging nature of her work. Her firm is successful and growing fast. As the firm has increased in size, the partners have worked to formalize policies and procedures. In most cases, the new rules were fine. In other cases, the new policies at were perceived as unfair or arbitrary. This was especially true when no input was requested from the professional staff. At Susan's level, she realized that she had little control over what the partners decided. If they asked her opinion, she would give it to them in a diplomatic manner. Otherwise she would either accept the situation or if necessary leave the firm and get a new job. There was no sense in getting worked up over minor policies that she had no control over.

As a member of the audit staff, Susan works with a number of different seniors, managers and partners, depending upon the client she works on. The senior runs the day to day activities of the engagement, tells her what to do, trains her, and reviews her work. A manager usually performs a detailed review of the work of the senior and staff. A partner in turn performs a big picture review of the work of the manager, senior and staff person. Similar structures exist in most large personal service firms and in industry.

As a professional, Susan likes to know what is expected of her, understand the big picture of why she is performing a particular task, know the process to be used, and have the tools and freedom necessary to complete the job. Like most professionals she expects to be treated with respect and not micro-managed. Susan enjoyed working with most of the seniors on her jobs. However a few were a challenge. Susan realized that not everyone is friendly, organized, knows what they are doing or can train and supervise others. Luckily, most of the engagements she is on only last a few weeks. Susan decided that she could put up with almost anything for a couple of weeks. In addition, she learned that she could review prior year workpapers and ask the senior, and other people within the firm, questions to clarify what is expected of her and how to do it.

Susan's experiences with being reviewed were mostly positive. The reviews were usually done in a professional tone and manner. Review points were written up and she in turn fixed the workpapers and addressed any issues that were overlooked the first time. Susan was warned by friends that graduated the year before, and in the accounting organization at school, that everyone gets review points. She viewed the review process as a learning experience. She remained friendly, avoided a defensive attitude, and made sure she did not repeat the same mistakes twice.

In cases where the tone and manner of the review were less professional, Susan didn't allow the reviewer to get under her skin. She remained professional and didn't take things personally. Instead she considered whether the comments were correct and whether she could learn from the experience. She also realized that the other person might be inexperienced or folding under pressure. If the reviewer started making inappropriate comments, she knew that she could ask the reviewer to "please keep it professional and let's stick to the issues." 
Unfortunately, not all new staff responded to reviewers the same way Susan did. Some new staff members took the review points personally, got defensive, pouted and argued with the senior, manger or partner. She noticed that pretty soon no one wanted the defensive people on their jobs. When staff auditors are not requested for jobs by seniors and managers, their days at a firm are numbered.

Susan was never sexually harassed or discriminated against, but knew she could report the behavior if it became necessary. She knew her firm's policies regarding office romance and relationships with clients. Based on her life experiences, she knew that most passes could be diplomatically dropped and a firmer approach could be taken if needed.

\section{Competition For Personal Rewards Or Organizational Resources}

Susan's firm stresses team cooperation, but also has a competitive side. The firm has an up or out environment. Public accounting offers outstanding training but is also very demanding. Employees are expected to learn quickly and to advance at a fast pace, or they will be advised to look for a new job. Turnover is high as not everyone is cut out for the hours and commitment necessary to succeed in public accounting.

Employees are expected to pass the CPA Exam as soon as possible and develop their technical skills quickly. By the second or third year, staff members are suppose to advance to senior level and start running jobs. This includes training, supervising and reviewing the work of staff. People skills become more important with each promotion. It is important to get along with people as auditors work in teams and deal with client personnel on a daily basis.

At lower levels, many employees view advancement as a survival process. They initially have little to say about which clients they work on. If they do good work, stay within time budgets, and avoid fatal mistakes, they expect to get promoted. Susan learned quickly and did the best she could on each job. She also worked well with others on her audit teams and avoided fatal mistakes.

At upper levels, promotion and compensation are more political and usually contingent upon bringing new business into the firm. In a CPA firm, competition usually exists between employees within the same level. For example, competition exists between staff, between seniors, between managers, and between partners.

In many cases the competition is healthy. People are pushed to continuously improve themselves and the firm as a whole. However, competition becomes unhealthy when people try to pull others down, instead of just doing the best that they can do. Unfortunately, some people resort to unethical behavior such as personal attacks, harassment, malicious gossip, blaming others, back-stabbing, withholding information or resources, faking agreement, sabotaging, and other forms of outright or guerilla warfare. These actions hurt company morale and encourage retaliation by the other party. In addition, other employees may be dragged into the fight and the loss of productivity hurts the firm as a whole.

At Susan's level, gossip and back-stabbing are the main threats from people that pull others down to make themselves look better. Susan has wisely not said anything to anyone that she did not want everyone in the firm to know. She watched her drinking at social occasions and kept any controversial activities and personal problems to herself. She also refused to be dragged into gossip sessions or to criticize her co-workers. Other staff were less careful and found their words and behaviors repeated and used against them.

In talking with John, Susan realized that he faced many of the same situations in industry that she did in public accounting. In addition, he observed more office politics and infighting, especially between different departments. Competition could be fierce for organizational resources such as budget funds, staff, and specific projects. By acquiring and controlling organizational resources, executives could increase their likelihood of gaining greater personal rewards such as increased compensation, recognition, and promotion. These rewards satisfy needs 
related to financial security as well as for power, prestige, and status. Upon reflection, Susan realized that within the CPA firm, seniors, mangers and partners competed for specific staff and clients for the same reasons.

At Susan's firm most new hires came in at close to the same compensation level. However, after the first year compensation levels started to vary more widely as the firm tried to reward and keep the high performers. The reward structure of the firm was designed to strongly influence behavior. In general, what gets rewarded gets repeated. Susan's firm values keeping clients happy by getting the job done within the time budget and before the due date. These things almost guarantee a steady stream of audit fees from happy clients. Employees are in effect profit centers. If members of the audit teams meet the goals, they survive and prosper. If not, they are gone after the first or second year.

John must also meet deadlines. Each month the books get closed and financial statements are prepared. However, at John's corporation, the accounting department is a cost center that supports other departments within the company. His company tries to increase it's profitability by increasing sales and controlling costs. It does not wish to pay more than necessary to ensure a specific level of quality performance throughout the organization. This value leads to competition and in-fighting between departments as they fight for resources and opportunities.

If the importance of teamwork is given lip service while only individual success is rewarded, then unhealthy competition is likely to develop. If employees do not feel adequately rewarded for their efforts and results and/or feel that they have no job security, then tensions and turnover are likely to be high. If the firm is not loyal to the employees, then the employees are unlikely to be loyal to the firm.

\section{CONFLICT RESOLUTION SKILLS FOR NEW STAFF ACCOUNTANTS AND AUDITORS: TEACHING NOTES}

\section{Diversity Issues:}

1. What attitudes lead to conflicts in workplaces with diversity?

Answer: Intolerance; being judgmental; assuming everyone should act and think the same; being defensive and assuming comments are intended as personal attacks; assuming that everyone has the same values and is motivated by the same things.

2. How would you avoid conflicts in a diverse workplace?

Answer: Respect other people's right to different; don't assume you know how they think, what they want, or what they meant by their tone or comments; ask questions to clarify what was intended to be said.

\section{Difficult People}

1. As a staff level professional, how would you deal with:

1A. Critical and judgmental people?

1B. Defensive and overly sensitive people?

1C. Negative people that complain constantly?

Answer: Avoid or ignore when possible; in extreme situations escape (change jobs or departments); control your own emotions and reactions; consider the truth of the message; ask questions; focus on solutions; if you are wrong, apologize; accept that people don't change unless they want to; if trapped in a conversation, change the subject or leave; realize that you don't have to answer inappropriate questions; turn the tables and ask them why they are asking the question or how would they solve the problem. 
1D. Bullies?

Answer: Realize that as an adult, there is little they can actually do to you; do not show intimidation or fear; continue to improve your skills and stay marketable; save enough to live on for several months, put it in a bank account, don't touch it unless a true emergency; report any workplace violence to management.

1E. Slackers (free-riders) and others that try to make their problems your problems?

Answer: Say No and stick to it; realize that you don't have to explain yourself.

\section{People Bringing Personal Problems To Work}

1. As a staff level professional, what would you do if a coworker had mental health, drug, or alcohol problems that interfered with their ability to do their work?

Answer: Expect management to deal with the problem; avoid if possible; do not take their comments personally; show compassion; if asked, recommend counseling; avoid getting sucked into problems your not equipped to deal with; don't do their work for them.

\section{Corporate Culture And Organizational Structure}

1. When looking for a job, why is it important to find a firm with a good fit?

Answer: You spend too much of your life at work to be with people you don't like or can't get along with; it is important to be where you are comfortable, get along with coworkers, fit in, can identify mentors, are respected and appreciated, and have opportunities for advancement.

2. As a staff level professional, how do you respond when your firm institutes policies or procedures that you don't like?

Answer: If asked, give your opinion in a diplomatic manner; otherwise either accept the situation or if necessary leave the firm and get a new job (there was no sense in getting worked up over minor policies that you have no control over).

3. As a staff level professional, how do you respond when you are micro-managed?

Answer: If the issues are minor, tolerate; realize that not everyone is friendly, organized, knows what they are doing or can train and supervise others; recognize that most engagements are for a limited time period; believe you can tolerate almost anything for a limited time period; if the issues are worth dealing with: politely ask for what you want and explain why it will help them get what they want; to get the big picture, review prior year workpapers and ask the senior and other people within the firm questions.

4. As a staff level professional, how do you respond when your work is reviewed and you do not feel that you were treated with enough respect?

Answer: Don't allow the reviewer to get under your skin; realize that the other person might be inexperienced or folding under pressure; remain professional; don't take things too personally; consider whether the comments were correct; learn from the experience; if the situation continues or gets worse, ask the reviewer to please keep it professional and let's stick to the issues.

5. As a staff level professional, how do you respond when a coworker shows sexual interest? 
Answer: Know firm policies regarding office romance and relationships with clients; if the interest is not mutual, drop the pass diplomatically; if the behavior is persistent, use a firmer approach; if necessary, report the behavior.

\section{Competition For Personal Rewards Or Organizational Resources}

1. What is the best way to compete at work?

Answer: Know the criteria that you will be evaluated on; do your best; be friendly, have a positive attitude; find mentors, make allies.

2. Should I sabotage my competitors with personal attacks, blame them for problems, spread malicious gossip, or withhold information or resources?

Answer: No; it can be effective in the short-term, however it will eventually backfire (you will not be trusted; will attract retaliation; will reduce overall firm productivity; you may become viewed as more trouble than your worth).

3. What should you do if you need information or additional resources to do your job?

Answer: Ask for what you need and persuade the holders of what you need to help you; if they still refuse, negotiate.

4. How would you persuade someone to help you?

Answer: Build rapport; explain or ask questions that lead the other person to conclude that doing what you want will help them and the firm; lead, assume they will do what you want and congratulate them on making the decision to proceed; offer alternatives such as "would they like to proceed with option A or would they prefer to go with option B;" if necessary, create fear of loss by noting that they will lose out, incur some type of cost, or that someone else will get the credit if they choose not to help you; if possible, take the risk out of the decision by asking them to "just give it a try" and that they can stop if it doesn't work out like you said it would.

\section{What if they aren't convinced?}

Answer: Ask questions to identify their objections; tie down their commitment if the objections can be overcome; clear up misunderstandings; turn their reasons not to proceed into the reasons to proceed; outweigh legitimate problems with the benefits of taking action; minimize the perceived costs of helping you by putting them in perspective with something they can relate to.

6. How would you negotiate with someone?

Answer: Identify what you want to accomplish; estimate a range regarding the most you could reasonably expect to get, what you are willing to settle for, and at what point you should walk away with no deal; estimate a best, worst, and most likely scenario for what you will need to give, in order to get what you want; asks questions to identify, probe and test the other party's real interests; make offers and counter-offers; don't overpay or give too much.

7. As a staff level professional, how would you respond when a coworker asks you if you like your job?

Answer: I love my job; never say anything you don’t want everyone in the firm to know.

8. As a staff level professional, how would you respond when a coworker asks what you think about a coworker or someone at a higher level? 
Answer: If positive, say it; if negative, change the subject; never say anything you don't want everyone in the firm to know.

9. As a staff level professional, how would you respond when coworkers start gossiping about or attacking a coworker or someone at a higher level?

Answer: Leave or change the subject; never join in or say anything you don't want everyone in the firm to know.

10. As a staff level professional, how would you behave at office parties and other events where alcohol was served?

Answer: If you drink, drink in moderation; stay in control; if you don't drink, do not have a condescending attitude towards those that do drink.

11. As a staff level professional, should you discuss any of your personal activities that are controversial or your personal problems with anyone at work?

Answer: No; never say anything you don't want everyone in the firm to know.

\section{REFERENCES}

1. Bell, A.H. \& D.M. Smith (1991). Winning with difficult people (Third Edition). Hauppauge, NY: Barron's Educational Series, Inc.

2. Bramson, R. (1992). Coping with difficult bosses. New York, NY: Fireside.

3. Brinkman, R. \& R. Kirschner (2002). Dealing with people you can't stand. New York, NY: McGraw-Hill, Inc.

4. Carnegie, D. (1981). How to win friends and influence people (Revised Edition). New York, NY: Pocket Books.

5. Cialdini, R. (1993). Influence: the psychology of persuasion. New York, NY: Quill William Morrow.

6. Cloke, K. \& J. Goldsmith (2005). Resolving conflicts at work: eight strategies for everyone on the job. San Francisco, CA: Jossey-Bass.

7. $\quad$ Dubrin, A.J. (1978). Winning at office politics. New York: NY: Ballantine.

8. Fisher, R., W. Ury \& B. Patton (1991). Getting to yes: negotiating agreement without giving in (Second Edition). New York: NY: Viking Penguin.

9. Harris, B. (2003). When your kids push your buttons: and what you can do about it. New York, NY: Warner Books, Inc.

10. Hogan, K. (1996). The psychology of persuasion: how to persuade others to your way of thinking. Gretna, LA: Pelican Publishing Company, Inc.

11. Oxman, M. (1997). The how to easily handle difficult people handbook. Corvallis, OR: Success Without Stress.

12. Pachter, B. \& S. Magee (2000). The power of positive confrontation: the skills you need to know to handle conflicts at work, home, and in life. New York, NY: Marlowe \& Company.

13. Schatzki, M. \& W. Coffey. (1981). Negotiation: the art of getting what you want. New York, NY: The New American Library, Inc.

14. Whiting, P. H. (1978). The 5 great rules of selling (Revised and Enlarged Edition): Garden City, NY: Dale Carnegie \& Associates, Inc. 